\title{
Special issue of theoretical ecology to honor Alan Hastings' 65th birthday
}

\author{
Stephen P. Ellner ${ }^{1} \cdot$ Louis J. Gross $^{2} \cdot$ Simon A. Levin ${ }^{3} \cdot$ Mark Lewis $^{4}$ \\ Published online: 25 May 2019 \\ (C) Springer Nature B.V. 2019
}

One of the greatest pleasures in a scientific career is to honor someone who has occupied a special place in one's life, and someone who has had a major impact on one's field through his own work, his mentorship, and his contributions to the scientific community. Alan Hastings is such a person, and one who has enriched our lives and careers and those of so many others for more than 45 years, from the time he was an undergraduate at Cornell University through graduate work and a brilliant career. Alan is noted not only for his exceptional and original contributions to ecology and evolutionary biology, contributions that have earned him numerous honors including election to the National Academy of Sciences and the American Academy of Arts and Sciences; he has also been a superb and generous mentor, beloved by his students, and a leader in scientific societies and the editorship of leading journals.

It is particularly satisfying to be able to honor our friend and colleague Alan Hastings on the occasion of his 65th birthday this year through two special issues: one of Theoretical Ecology, a journal Alan conceived,

Simon A. Levin

slevin@princeton.edu

1 Department of Ecology and Evolutionary Biology, Cornell University, Ithaca, NY 14853, USA

2 Department of Ecology and Evolutionary Biology, University of Tennessee, Knoxville, TN 37996, USA

3 Department of Ecology and Evolutionary Biology, Princeton University, Princeton, NJ 08544, USA

4 Department of Mathematical and Statistical Sciences and the Department of Biological Sciences, University of Alberta, 632 CAB, Edmonton, AB T6G 2G1, Canada founded, and continues to edit; and the other of the Journal of Mathematical Biology, which Alan coedited for many years. Of course, in so doing, we had to bypass Alan and go directly to his many students, postdocs, and colleagues, and invite them to contribute; the details of who the contributors are will thus come as a surprise to Alan, who had nothing to do with the invitations or reviewing. Alan was not only editor of those two journals, but also co-editor of the Encyclopedia of Theoretical Ecology, the author of one of the most successful textbooks of theoretical ecology, and a very successful and popular department chair at UC Davis.

Hastings has been a leading force in theoretical ecology for decades and has helped lay the foundation for scientifically-based agriculture and resource management. Increasingly, the core agricultural disciplines such as entomology to agricultural economics are utilizing ecological principles as a fundamental driver to new insights. In large part, this is because of people like Alan Hastings, whose work spans so many disciplines and reaches from the very basic to the very applied. Alan is distinguished for his research, as well as for his commitment to advancing the basic ecological sciences and their management implications.

The scope of Hastings's work has been remarkable across the spectrum of ecology and evolution. He has produced a superb and daunting set of publications that make him one of the most respected theoretical ecologists in the world. With over 25,000 citations (Google Scholar), he is among the elite in his subject and earned that position by repeatedly making pathbreaking contributions to important topics in ecology. Alan's approach to science is strikingly original. His hallmark has been to pioneer the use of mathematics in solving ecological 
problems, an approach he adopts long before others realize the role that mathematics can actually play in the solutions to those problems. Thus, many of his papers define significant new areas of research, and along the way have become citation classics.

Alan's early contributions include cornerstone papers on population dynamics in stochastic environments and the role of patchiness that not only led to major advances in theory, but also deeply influenced practice in species conservation. His work includes fundamental theoretical papers on multi-locus population genetics, population cycles, transient dynamics, food web stability, structured metapopulation models, and invasive species spread. His mathematical work is rigorous and brilliantly original, but he has also demonstrated the ability to work closely with empiricists and managers and brought the full power of sophisticated advances to bear on applied problems including pest outbreaks, exploited resource populations, and control of invasive species. He has trained numerous outstanding young (and formerly young) scientists, and all speak warmly of his influence.

Alan Hastings's research shows a lifetime of commitment to the betterment of society. It is our honor and privilege to have put this special issue together. Happy Birthday, Alan. 